\title{
PM measurement campaign HOVERT in the Greater Berlin area: model evaluation with chemically specified particulate matter observations for a one year period
}

\author{
M. Beekmann ${ }^{1}$, A. Kerschbaumer ${ }^{2}$, E. Reimer ${ }^{2}$, R. Stern ${ }^{2}$, and D. Möller ${ }^{3}$ \\ ${ }^{1}$ Laboratoire Interuniversitaire de Systèmes Atmosphériques (LISA), CNRS UMR 7583, University Paris 7, University Paris \\ 12, 61 Av. du Général de Gaulle, 94000 Créteil, France \\ ${ }^{2}$ Freie Universität Berlin, Institut für Meteorologie, Carl-Heinrich-Becker-Weg 10, 12165 Berlin, Germany \\ ${ }^{3}$ BTU Cottbus, Lehrstuhl für Luftchemie und Luftreinhaltung, Burger Chaussee 2, 03044 Cottbus, Germany
}

Received: 22 March 2006 - Published in Atmos. Chem. Phys. Discuss.: 2 August 2006

Revised: 15 November 2006 - Accepted: 29 November 2006 - Published: 10 January 2007

\begin{abstract}
The HOVERT (HOrizontal and VERtical Transport of ozone and particulate matter) campaign held in the Berlin Brandenburg area in Eastern Germany from September 2001 to September 2002 allowed to collect a unique data set of the aerosol chemical speciation (daily averages) at traffic, urban and rural sites. These observations are used for a thorough evaluation of the aerosol part in the REMCALGRID model (RCG) developed at the Free University of Berlin (FUB). For inorganic ions (sulphate, nitrate and ammonium), simulated annual averages agree to observations within $\pm 30 \%$ at more than half of the sites and always within a factor of two. Correlation coefficients are larger than in previous studies for $\mathrm{SO}_{4}^{2-}$ and $\mathrm{NH}_{4}^{+}(>0.7)$. For nitrate, less elevated correlations, $0.4-0.7$ in the cold season, $0.2-0.4$ in the warm season, are encountered. To our knowledge, this is one of the first comparisons of air quality model simulated elemental and organic carbon (EC and OC) with daily observations for a whole year. It suggests an overestimation of $\mathrm{EC}$ and $\mathrm{OC}$ emissions in the Berlin area (through a scaling techniques between $\mathrm{EC}, \mathrm{OC}$ and $\mathrm{NO}_{\mathrm{x}}$ and when assuming correct $\mathrm{NO}_{\mathrm{x}}$ emissions), and an underestimation of $\mathrm{EC}$ and $\mathrm{OC}$ at rural sites. Secondary organic aerosol (SOA) formation, recently introduced into the model (SORGAM module, Schell et al., 2001), is simulated as a very variable process, SOA levels varying from close to zero for most days to more than $5 \mu \mathrm{g} / \mathrm{m}^{3}$. Correlation between simulated SOA to observed $\mathrm{OC}$ is about 0.6 , indicating that simulated variability partly corresponds to reality.
\end{abstract}

Correspondence to: M. Beekmann

(beekmann@lisa.univ-paris12.fr)

\section{Introduction}

Precise knowledge of the chemical and size speciation of particulate matter (PM) is mandatory in order to correctly address the potential health impact related to particulate matter pollution. These speciations depend on a variety of physicochemical processes: the secondary inorganic ions (SIA) sulphate, nitrate and ammonium are chemically produced from their precursor gases $\mathrm{SO}_{2}, \mathrm{NO}_{\mathrm{x}}$ and $\mathrm{NH}_{3}$. Secondary organic aerosol (SOA) is produced from oxigenated VOC with low vapour pressure. These latter two processes imply mass transfer from the gas to the aerosol phase. Elemental and primary organic carbon is directly emitted into the atmosphere. The mineral PM fraction is due to dust entrainment. Coagulation of particles will determine their size distribution. Last not least wet and dry deposition represent important sink processes.

Air quality model evaluation studies using chemically specified PM data for secondary inorganic ions from the EMEP network are presented in a number of papers (Hass et al., 2003; Bessagnet et al., 2004; Schaap et al., 2004a; Tørseth et al., 2004). For most of the sites and most of the models, simulated sulphate, nitrate and ammonium summer and winter averages agree within a factor of two to observations. For nitrate and ammonium, routine measurements for only about 10 sites were available; it was thus not possible to discern spatial patterns in the differences. Thus, focussed regional studies with a dense measurement network working over several seasons would greatly enhance the observational basis for evaluation of inorganic ion simulations.

Only a few model evaluation studies include the carbonaceous fraction of aerosols. This is due to the paucity of suitable observational and emission data (see a compilation of

Published by Copernicus GmbH on behalf of the European Geosciences Union. 
European EC and OC measurements in Putaud et al., 2004), and because the carbonaceous fraction was only recently included in air quality models in enough detail.

An additional difficulty in these studies is that, while elemental or black carbon (EC or BC) is of primary origin, organic carbon (OC) is both of primary and of secondary origin, and both parts can not be discerned by conventional thermal or optical measurement techniques. Processes of SOA formation from oxygenated VOC, as well as removal processes and the climate relevance of SOA have recently been reviewed by Kanakidou et al. (2005). These complex processes are highly parameterised in models (e.g. Schell et al., 2001). In a recent paper Yu et al. (2004) have derived primary OC for several measurement sites in the U.S. using source appointment methods and then compared observation derived primary OC/EC ratios to model derived ones. EC and OC have recently been introduced also in the Unified EMEP model (Tørseth et al., 2004); first evaluation with a limited set of data over Europe (five sites) showed a large underestimation of simulated EC and OC (typically by about a factor two and more), which could, following the authors, be due to missing emission sources in the used inventory (Tørseth et al., 2004; Yttry et al., 2005). Schaap et al. (2004b) derived an emission inventory for EC and primary fine aerosol for Europe, and used it to simulate EC and primary PM distributions. They found a model underestimation of a factor of two or more with respect to available EC measurements, which they also attributed to probably too low emissions. A comparison between CTM model output and aerosol Raleigh lidar measurements at a suburban site near Paris led to the suggestion that SOA could be strongly underestimated by the model (Hodzic et al., 2004). Clearly, in this field much more work is needed both on the observational and modelling side.

The German AFO-2000 HOVERT campaign aimed at increasing the observational data basis for chemically and size specified aerosols in a Central European region with strong anthropogenic influence, the Berlin Brandenburg area. Dedicated daily measurements in a network of about ten traffic, urban, peri-urban and rural sites for an about one year period (from September 2001 to September 2002) provided valuable information to assess the urban/regional contrast in concentrations, sources of different aerosol components and to perform a thorough model evaluation. The HOVERT data base is enhanced by routine observations from the regional Berlin and Berlin-Brandenburg air quality networks and from specific measurements at a traffic influenced site in Berlin, supported by the SENAT of Berlin.

The RCG-model, developed at Free University of Berlin with the support of the German Environmental Protection Agency (Umweltbundesamt) (Stern, 2003), is a ChemistryTransport-Model of medium complexity designed for the regional and urban scale. In the past, RCG has been mainly used for the simulations of emission abatement scenarios (Stern, 2003) and for ozone forecast (http://www.trumf.de) (Tilmes et al., 2001). Model evaluation was performed mainly within the framework of several European model inter-comparison studies (Stern et al., 2003; Hass et al., 2003; Roemer et al., 2003; Van Loon et al., 2004).

In this paper, the HOVERT data base is used for a thorough evaluation of the aerosol part of RCG employing an urbanscale model run over the Berlin Brandenburg area which was nested into an European-scale model run. First, special emphasis will be given on the evaluation of the urban/regional contrast in the simulations, i.e. to know if the model is capable to correctly represent both the production processes of particulate matter within an urban area (Berlin), and long range transport into that area. In an accompanying paper, Kerschbaumer et al. (2007) ${ }^{1}$ build on this model evaluation and use RCG for budget analysis of aerosol formation, transport and loss processes within the Berlin area. Second, we will focus on the evaluation of simulations of carbonaceous species which have been recently introduced into RCG, but which have to be considered still as "tentative", in particular because of uncertain emission data for primary OC.

The paper is organised in the following way: the RCG model set-up is explained in the following section; in Sect. 3, the observational data base is briefly presented; Sect. 4 is devoted to results of the model/observation comparisons, distinguishing between analysis of annual averages, the seasonal variation, and day to day variability; in Sect. 5, possible reasons for differences between simulations and observations are discussed focussing in particular on the carbonaceous aerosol fraction; conclusions will be given in Sect. 6 .

\section{Model design}

\subsection{General}

REM-CALGRID is an urban/regional scale model development designed to fulfil the requirements of the ambient air quality framework directive 96/62/EC of the European Commission (Stern et al., 2003). Rather than creating a completely new model, the urban-scale photochemical model CALGRID (Yamartino et al., 1992) and the regional scale model REM3 (Stern, 1994; Hass et al., 1997) were used as the starting point for the new urban/regional scale model, REM-CALGRID (RCG). The premise was to design an Eulerian grid model of medium complexity that can be used on the regional and the urban scale for short-term and long-term simulations of oxidant and aerosol formation.

The model includes the following features:

- A generalized horizontal coordinate system, including latitude-longitude coordinates;

\footnotetext{
${ }^{1}$ Kerschbaumer, A., Beekmann, M., and Reimer, R.: PM Measurement campaign HOVERT: mass balancing with the chemical transport model REM CALGRID, Atmos. Chem. Phys. Discuss., in preparation, 2007.
} 
- A vertical transport and diffusion scheme that correctly accounts for atmospheric density variations in space and time, and for all vertical flux components when employing either dynamic or fixed layers;

- A new methodology to eliminate errors from operatorsplit transport and to ensure correct transport fluxes, mass conservation, and that a constant mixing ratio field remains constant;

- Inclusion of the recently improved and highly-accurate, monotonic advection scheme developed by Walcek (2000). This fast and accurate scheme has been further modified to exhibit even lower numerical diffusion for short wavelength distributions;

- The latest releases of the SAPRC-93 and CBM-IV photochemical reaction schemes;

- Two equilibrium aerosol modules, that treat the thermodynamics of inorganic aerosols;

- An equilibrium aerosol module, that treats the thermodynamics of organic aerosols;

- Simple modules to treat the emissions of sea salt aerosols and wind blown dust particles;

- A simple wet scavenging module based on precipitation rates;

- An emissions data interface for long term applications that enables on-the-fly calculations of hourly anthropogenic and biogenic emissions.

\subsection{Model domains}

The RCG large scale model domain covers approximately the political Europe (EU25) ranging from $-10^{\circ} \mathrm{W}$ to $30^{\circ} \mathrm{E}$, and from $35^{\circ} \mathrm{N}$ to $66^{\circ} \mathrm{N}$, with a resolution of $0.25^{\circ}$ in latitude and $0.5^{\circ}$ in longitude. The nested domain covers the Berlin Brandenburg area $\left(12^{\circ} \mathrm{E}-15^{\circ} \mathrm{E}, 53.5^{\circ} \mathrm{N}-55.5^{\circ} \mathrm{N}\right)$ with a 4 $\mathrm{km}$ horizontal resolution. The model was run in the dynamic layer mode with five vertical layers. In this mode, the position of the layers follows the planetary boundary layer height, except the terrain following $20 \mathrm{~m}$ thick surface layer. Two dynamic equal-thickness layers are below the mixing height, and two above the mixing height and extending to the domain top at $3000 \mathrm{~m}$.

\subsection{Meteorology}

Meteorological data needed by RCG at hourly intervals consist of layer-averaged gridded fields of wind, temperature, humidity and density, plus 2-D gridded fields of mixing heights, several boundary layer and surface variables, precipitation rates and cloud cover. All this meteorological data is produced employing a diagnostic meteorological analysis
Table 1. EC emission ratios of $\mathrm{PM}_{2.5}$ emissions for different SNAP sectors from (Builtjes et al., 2003).

\begin{tabular}{ll}
\hline Sector & $\begin{array}{l}\text { EC fraction of } \\
\mathrm{PM}_{2.5} \text {-Emissions } \\
\left(\mathrm{f}_{\mathrm{EC}}\right)\end{array}$ \\
\hline Power generation & 0.12 \\
Residential, commercial and other combustion & 0.2 \\
Industrial combustion & 0.13 \\
Industrial processes & 0 \\
Extraction, distribution fossil fuels & 0.79 \\
Road transport & 0.47 \\
Other mobile sources & 0.49 \\
Waste treatment and disposal & 0.004 \\
\hline
\end{tabular}

system based on an optimum interpolation procedure on isentropic surfaces developed at Freie Universität Berlin. The system utilizes all available observed synoptic surface and upper air data (Kerschbaumer and Reimer, 2003; Reimer and Scherer, 1992).

\subsection{Emissions}

RCG model requires annual emissions of VOC, $\mathrm{NO}_{\mathrm{x}}, \mathrm{CO}$, $\mathrm{SO}_{2}, \mathrm{CH}_{4}, \mathrm{NH}_{3}, \mathrm{PM}_{10}$, and $\mathrm{PM}_{2.5}$, split into point and gridded area sources. Mass-based, source group dependent NMVOC profiles are used to break down the total VOC into the different species classes of the chemical mechanisms. Hourly emissions are derived during the model run using sector-dependent, month, day-of-week and hourly emission factors. European-wide annual anthropogenic emission averages for 2000 for $\mathrm{CO}, \mathrm{NO}_{\mathrm{x}}, \mathrm{NMVOC}, \mathrm{SO}_{\mathrm{x}}, \mathrm{NH}_{3}$ and $\mathrm{PM}_{10}$ on a $50 \mathrm{~km} \times 50 \mathrm{~km}$ grid are taken from the EMEP data base (Vestreng, 2003) and were transformed into the geographical RCG-grid. For the nested region Berlin/Brandenburg, highly resolved emissions data were obtained from regional administrations. To ensure consistency between the urban/regional-scale and the continental-scale emissions, the Berlin/Brandenburg data were scaled sector-by-sector and species by species to the level of the EMEP data.

$\mathrm{PM}_{10}$ emissions were split into a $\mathrm{PM}_{2.5}$ and a coarse PM $\left(\mathrm{PM}_{10}-\mathrm{PM}_{2.5}\right)$ part, the $\mathrm{PM}_{2.5}$ part was further split into mineral dust, $\mathrm{EC}$ and primary $\mathrm{OC}$. $\mathrm{EC}$ fractions in $\mathrm{PM}_{2.5}$ emissions for different SNAP sectors given in Table 1 were taken from Builtjes et al. (2003) and are discussed in detail in Schaap et al. (2004b). For primary OC, no such factors exist to our knowledge for Europe. Thus the following crude method was applied to estimate these emissions in a preliminary way: In the $1996 \mathrm{NEI}$ emission data base

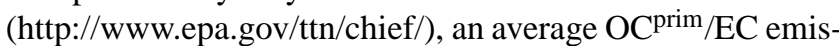
sion ratio for all sectors of about two can be derived for the U.S. This ratio was then applied to Europe regardless of the SNAP sector, i.e. the OC fractions were set as the double of the EC fractions indicated in Table 1, except if the sum 
of the two factors would be larger than unity. In this case $\left(f_{E C}>0.33\right), f_{O C}$ was set as: $f_{O C}=1-f_{E C}$. For example, for mobile sources $\mathrm{f}_{\mathrm{EC}}$ and $\mathrm{f}_{\mathrm{OC}}$ are then nearly equal which is consistent with the global emission inventory from Bond et al. (2004) which attributes about respectively 2.4 to $3 \mathrm{Tg}$ OC and EC emissions to fossil fuel burning among which transport is a major source. Nevertheless, the allocations of OC emission fractions are crude as they relate the spatial distribution of primary $\mathrm{OC}$ to that of $\mathrm{PM}_{2.5}$ without taking into account specific patterns of OC emissions. Anyway, a gridded OC inventory did not exist for Europe at the time of the study.

Biogenic VOC-emissions are derived using the E94 emissions factors for isoprene and OVOC (Other VOC) as described in Simpson et al. (1995). Terpene emission factors are taken from the CORINAIR emission hand-book. These biogenic calculations are based on the land-use data for deciduous, coniferous, mixed forests and crops. Light intensity and temperature dependencies are also considered. Soil NO emissions are calculated as a function of fertilizer input and temperature following Simpson et al. (1995).

\subsection{Chemistry}

An updated version of the lumped chemistry scheme CBM4 (Gery et al., 1989), including Carter's 1-Product Isoprene scheme (Carter, 1996), was used for the simulations. Homogeneous and heterogeneous conversion of $\mathrm{NO}_{2}$ to $\mathrm{HNO}_{3}$ is added. In addition to gaseous phase, also simple aqueous phase conversion of $\mathrm{SO}_{2}$ to $\mathrm{H}_{2} \mathrm{SO}_{4}$, through oxidation by $\mathrm{H}_{2} \mathrm{O}_{2}$ and ozone, has been incorporated. Equilibrium concentrations for $\mathrm{SO}_{2}, \mathrm{H}_{2} \mathrm{O}_{2}$ and ozone are calculated using Henry constants from Seinfeld and Pandis (1998) and assuming progressive cloud cover for relative humidity above $80 \%$. Effective rate constants for the aqueous phase reactions $\mathrm{SO}_{2}+\mathrm{H}_{2} \mathrm{O}_{2}$ and $\mathrm{SO}_{2}+\mathrm{O}_{3}$ have been calculated for an average $\mathrm{pH}$ of 5 using acid / base equilibria and kinetic data from Seinfeld and Pandis (1998). The pH of 5 is close to annual averages in rain samples collected at many European EMEP sites (http://www.nilu.no/projects/ccc/emepdata.html). Due to uncertainties in cloud liquid water content, $\mathrm{pH}$, and gas phase $\mathrm{H}_{2} \mathrm{O}_{2}$ levels, aqueous phase $\mathrm{SO}_{2}$ to $\mathrm{SO}_{4}^{2-}$ conversion rates are relatively uncertain, but this is a common feature for air quality models.

For numerical solution of the chemistry differential equations system, the QSSA chemistry solver with a variable time step control is used.

\subsection{Aerosol treatment}

In RCG, different chemical fractions are considered to contribute to $\mathrm{PM}_{10}$, i.e. particulate matter with a dynamical diameter up to $10 \mu \mathrm{m}$ :

$\mathrm{PM}_{10}=\mathrm{PM}_{\text {coarse }}+\mathrm{PM}_{2.5}^{\text {prim }}+\mathrm{EC}+\mathrm{OC}^{\text {prim }}+\mathrm{SOA}$

$$
+\mathrm{SO}_{4}^{2-}+\mathrm{NO}_{3}^{-}+\mathrm{NH}_{4}^{+}+\mathrm{Na}^{+}+\mathrm{Cl}^{-}
$$

For efficiency reasons, a bulk approach is used, i.e. the major PM constituents are treated as a single model species with a given log-normal size distribution. For the majority of species, its geometrical average is set to $0.48 \mu \mathrm{m}$ (with a geometric standard deviation of a factor of two), corresponding to the accumulation mode. For $\mathrm{PM}_{\text {coarse }}$ (mineral coarse particles between 2.5 and $10 \mu \mathrm{m}$ diameter), sodium and chloride (sea salt), the diameter is set to $4-5 \mu \mathrm{m}$ with a geometric standard deviation of a factor of 3 .

The equilibrium between solid, aqueous and gas phase concentrations for inorganic ions as a function of temperature and humidity is calculated on-line with the ISORROPIA thermodynamic module, which is optimised for urban and regional pollution conditions (Nenes et al., 1999). Production of secondary organic aerosol (SOA) from anthropogenic and biogenic VOC is treated with the SORGAM module (Schell et al., 2001) which calculates the partitioning of semivolatile organic compounds produced during VOC oxidation between the gas and the aerosol phase. For each parent VOC, the module assumes two distinct oxidation products of different saturation vapour pressure (Odum et al., 1996). This module, originally used in the EURAD model in conjunction with the RADM chemical module, was adapted to be used with CBM-4. To this purpose, terpenes ( $\alpha$-pinene and limonene) were added to the chemical scheme.

The aerosol scheme also includes resuspension of mineral aerosol as a function of friction velocity and the nature of soil; both the direct entrainment of small particles (Loosemore and Hunt, 2000) and saltation, i.e. the indirect entrainment due to large particles which fall back to the soil and entrain smaller particles (Claiborn et al., 1998) is taken into account. The sea-salt aerosol emissions $\left(\mathrm{Na}^{+}, \mathrm{Cl}^{-}\right)$are parameterized according to Gong et al. (1997) as a function of size and wind speed.

\subsection{Dry and wet deposition}

Dry deposition for gaseous species and particles is calculated using the resistance analogy. Turbulent and laminar resistance are calculated following Padro (1993) from surface roughness, Monin-Obukhov length, friction velocity, molecular diffusivity. Surface resistance is computed following Erisman and Pul (1994) for different surfaces (leaves, soils, ....) taking into account species dependent (Henry constant, oxidation power), micro-meteorological (leaf temperature, radiation, ....), and land-use (agricultural land, grass land, forest, ....) information. For particles, surface resistance is zero. The atmospheric resistances are large for particles in the accumulation mode $(0.1 \mu \mathrm{m}<\varnothing<1 \mu \mathrm{m})$, because neither Brownian motion, nor sedimentation are effective pathways; these resistances are calculated for the different species using the fixed size distributions given above. Wet deposition of gases due to in and below cloud scavenging is parameterized as a function of the species dependent Henry constant and 
Table 2. Characteristics of measurement sites relevant for this study.

\begin{tabular}{lllll}
\hline Name of the site & Acronym & Location & Type & Measurement periods ${ }^{1}$ \\
\hline Frankfurter Allee & MP 174 & Berlin urban area & Traffic & OC >May 2002 \\
Beusselstrasse & BS & Berlin urban area & Traffic & All $>$ July 2002 \\
Nansenstrasse & MP42 & Berlin urban area & Urban background & OC > May 2002 \\
Schichauweg & MP27 & Edge of urban area - north & Suburban & OC > May 2002 \\
Wiltbergstrasse & MP77 & Edge of urban area - south & Suburban & OC >May 2002 \\
Paulinenaue & PA & Brandenburg & Rural & All $>$ Jan, OC $>$ Feb 2002 \\
Hasenholz & HH & Brandenburg & Rural & All $>$ Feb 2002 \\
Lebus & LB & Brandenburg & Rural & Only weekly PM $10+$ EC \\
Neuglobsow & NG & Brandenburg & Rural & Only PM 10 \\
\hline
\end{tabular}

1 measurement periods: by default observations from October 2001 to September 2002 are used.

the precipitation rate. Wet deposition of particles is treated in RCG using a simple scavenging coefficient approach. For $\mathrm{EC}$ and $\mathrm{OC}$ the same value as for sulphate is chosen, i.e. $10^{-4} \mathrm{~s}^{-1}$. This factor implies that the particles immediately become hydrophilic.

\section{Description of observational data set}

During the HOVERT campaign (September 2001September 2002), nine special observational sites in the Berlin and Brandenburg area (Fig. 1, Table 2) were equipped with dedicated instruments to perform daily measurements of $\mathrm{PM}_{10}$ and its chemical speciation, including inorganic ions, elemental and organic carbon. Two traffic sites (Frankfurter Allee MP174, Beusselstr. BS) were chosen in the centre of Berlin, one urban background site (Nansenstr. MP42) was installed within the urban area (some $\mathrm{km}$ south-east of the town centre), two suburban sites (Schichauweg MP27, Wiltbergstr. MP77) were placed at the southern and northern edge of the urbanised area, four rural sites (Paulinenaue PA, Hasenholz HH, Lebus LB, Neuglobsdorf NG) and one tower in the North of Berlin (Frohnau, $321 \mathrm{~m}$ height) were installed in order to obtain an rural counterpart to the urban samples. Measurement sites were often part of regional or national air quality networks. Measurements started right in September 2001 at the urban and suburban sites Schichauweg, Nansenstr., Wiltbergstr. and Frankfurter Allee and were after several months extended to other measurement stations (Paulinenaue in January 2002, Hasenholz in February, Beusselstr. in July). OC measurements are available from May 2002 on. At Lebus, only $\mathrm{PM}_{10}$ and EC are available, at Hasenholz only $\mathrm{PM}_{10}$. Samples from the suburban sites Schichauweg and Wiltbergstr. have been analysed depending on the wind direction in order to sample cases with minimal pollutions from the town (for about half of the cases), in order to obtain regional background levels.

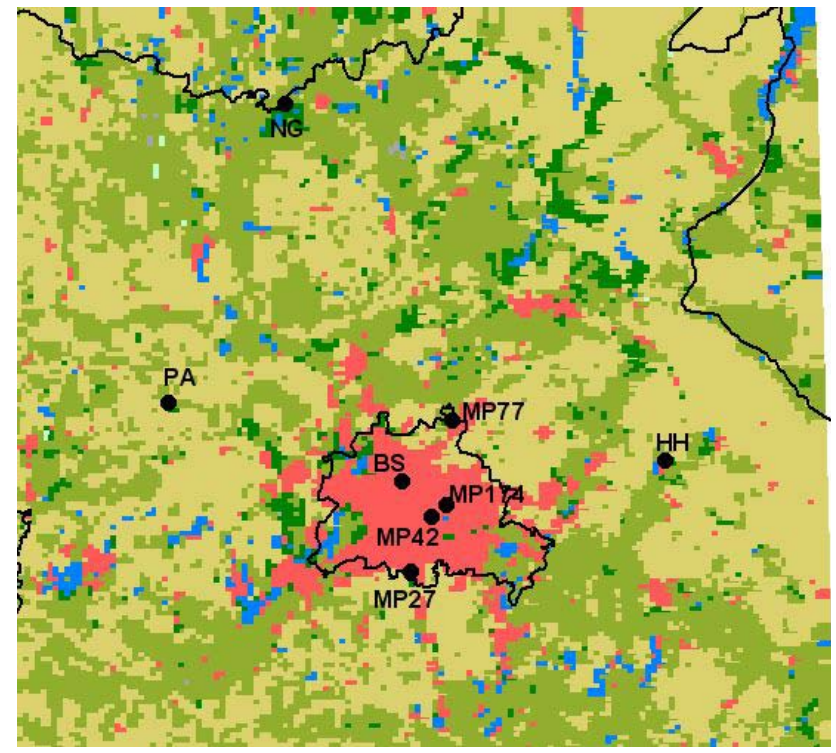

Fig. 1. Location of measurement sites relevant for this study and land use classes in the nested urban model domain: urban (red), forest (green), water (blue), agricultural and bar land (yellow). See Table 2 for acronyms.

By means of a DIGITEL High-Volume-Sampler, daily samples of atmospheric $\mathrm{PM}_{10}$ fractions have been collected on quartz filters conditioned according to usual regulations. Subsequently, filter parts were chemically analysed by means of ion chromatography (SYKAM) in order to measure main ions (sulphate, nitrate, chloride, potassium, magnesium, calcium, ammonium) as well as by means of thermographimetry to measure EC (elemental carbon) and OC (organic carbon), following VDI regulation 2564, Blatt 2. In this method, elemental (EC) and organic carbon (OC) are determined from one and the same filter sample using the sequential thermal desorption properties of OC and EC and applying an IRdetection of the developed $\mathrm{CO}_{2}$. In a first step, the sample is heated gradually in a helium-atmosphere up to $600^{\circ}$ Celsius 

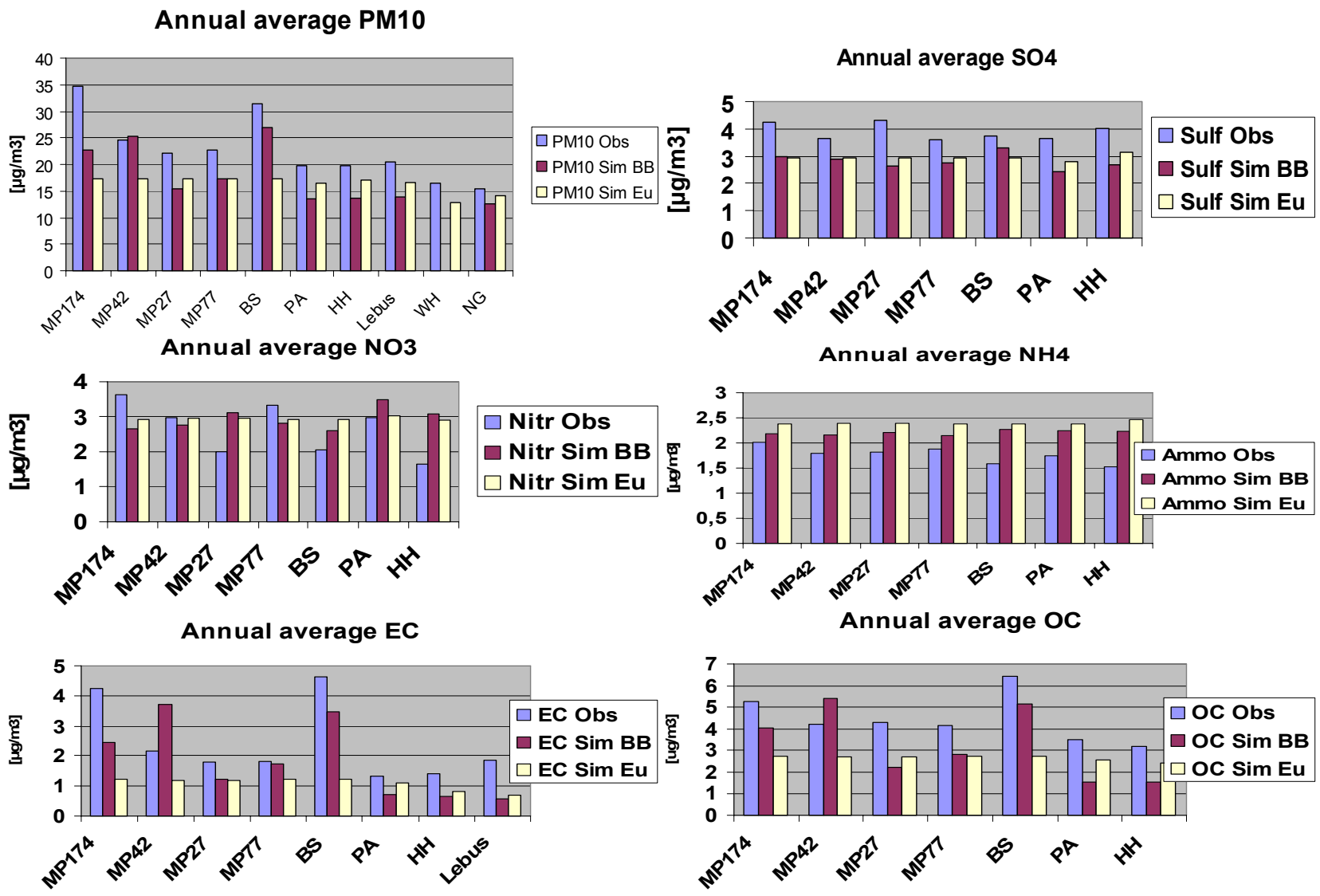

Fig. 2. Observed and simulated (with the urban and continental scale model) annual averages for PM 10 , Sulphate, Nitrate, Ammonium, EC and OC. BB denotes nested simulations in the Berlin-Brandenburg area, EU European wide simulations.

evaporating organic $\mathrm{C}$-compounds, which are then catalytically transformed into $\mathrm{CO}_{2}$. In a second step, EC is transformed into $\mathrm{CO}_{2}$ in a $20 \% \mathrm{O}_{2} / 80 \% \mathrm{He}$ atmosphere. Moreover, trace metals $(\mathrm{Fe}, \mathrm{Cu}, \mathrm{Zn}$, etc.) were analyzed by ICP mass spectroscopy, but these measurements are not exploited in this paper (as they are not included in the RCG model).

Systematic quality checks of the measurements were performed during and after the campaign, including comparison between sampling methods (high and low volume samplers) and in particular the temperature dependence of the EC, OC determination with the VDI method (John and Kuhlbusch, 2004). The comparability of the different methods was in general satisfying, with differences below 10 to $15 \%$. Nevertheless, systematic uncertainties remain, which could not directly be tested. In particular, evaporation of nitrate (and ammonium) above about $20^{\circ} \mathrm{C}$ outside temperature (e.g. Schaap et al., 2004a) can lead to a substantial (but difficult to quantify) underestimation of these ions especially in summer. During an intercomparison campaign at a Dutch rural sites, total carbon measurements obtained with high volume samplers agreed within 10\% (ten Brink et al., 2004). However, EC measurements performed after the VDI 2564/2 method as in our study showed larger values than the average (about $50 \%$ ), while OC measurements showed lower values (about 25\%) than the average. Rather than indicating a systematic bias in one of the methods used in this study, these results indicate the range of measurement uncertainty which can be reasonably expected for this type of measurements.

\section{Model evaluation}

\subsection{Annual averages}

In this section, simulated annual averages for $\mathrm{PM}_{10}$, sulphate, nitrate, ammonium, EC and OC are compared to observations from the HOVERT campaign. For inorganic ions, differences in the annual averages are below $\pm 30 \%$ for the majority of sites and always within a factor of two (Fig. 2). Results are similar for the nested simulations with $4 \mathrm{~km}$ horizontal resolution and for the continental scale simulations with about 25 to $30 \mathrm{~km}$ resolution indicating that processes within the urban area do not much affect secondary inorganic aerosols (SIA). This is also apparent from the similar concentrations at different sites in the simulations and to 
a lesser extent in the observations. On the other hand, in agreement with the observations, the nested run exhibits a distinct urban-rural concentration gradient for primary particles, $\mathrm{SO}_{2}$ and $\mathrm{NO}_{\mathrm{x}}$ levels (not shown for $\mathrm{SO}_{2}$ and $\mathrm{NO}_{\mathrm{x}}$ ) because of the better representation of the urban-rural emissions contrast. The regional scale run is not able to capture this urban signal because the urban-rural concentration gradient of primary pollutants is diffused due to the high spatial aggregation of the emissions. However, the time scale related to the $\mathrm{SO}_{2}$ to $\mathrm{SO}_{4}^{2-}$ and $\mathrm{NO}_{\mathrm{x}}$ to $\mathrm{NO}_{3}^{-}$transformation (several hours to several days) is large enough to make differences in the grid resolution unimportant for SIA formation. For sulphate, simulations systematically underestimate observations, from $-11 \%$ to $-39 \%$. For nitrate, differences range from $-26 \%$ to $+86 \%$. While for traffic, urban and suburban sites, no systematic tendencies appear, simulations show an overestimation for the two rural sites Paulinenaue and Hasenholz. For ammonium, differences range from $+8 \%$ to $+46 \%$, with again more pronounced overestimation for the rural sites. Thus, especially for the urban sites, there is an opposite tendency for sulphate and ammonium, i.e. observed aerosols are more acid than simulated ones. On the contrary, the sum of SIA (sulphate + nitrate + ammonium) averaged over all sites is very similar in simulations $\left(8.0 \mu \mathrm{g} / \mathrm{m}^{3}\right)$ and observations $\left(8.3 \mu \mathrm{g} / \mathrm{m}^{3}\right)$.

EC is underestimated in the nested simulations at the traffic sites Frankfurter Allee and Beusselstrasse (by -42 and $-25 \%$, respectively). This behaviour can be expected, because the model with a $4 \mathrm{~km}$ horizontal resolution is not designed to resolve local EC emission sources in street canyons. On the contrary, at the urban background site Nansenstrasse, EC is overestimated (by $+72 \%$, always with the nested model). For the suburban sites, Schichauweg and Wiltbergstr., there is no clear tendency, while for the three rural sites, EC is underestimated (between $-45 \%$ and $-69 \%$ ). For EC, as for OC, differences between the large scale and the nested simulations can be large: the nested simulations show larger values for inner-urban sites, but smaller ones for rural sites.

For OC, a qualitatively similar behaviour as for EC is observed. OC is underestimated at traffic sites $(-48$ and $-58 \%)$, overestimated at the urban background site $(+29 \%)$, and underestimated at town edge and rural sites (between $-5 \%$ and $-69 \%$ ). The similar behaviour of OC and EC may be explained by the fact that about $60 \%$ of simulated OC at rural sites and over $80 \%$ at urban sites are of primary origin and that primary $\mathrm{OC}$ and $\mathrm{EC}$ have similar emission sources (combustion).

Simulated $\mathrm{PM}_{10}$ is underestimated for most of the HOVERT sites (from $-34 \%$ to $+3 \%$ ), the strongest underestimation occurring, as expected, at the traffic site Frankfurter Allee (always for nested simulations). This good agreement partly reflects the good agreement for the sum of secondary organic ions, which make up more than a third of $\mathrm{PM}_{10}$. It also reflects uncertainties in the quality of the emis- sions database. This is particularly true for $\mathrm{PM}_{10}$, because the uncertainties in the emissions estimates for particulates are larger than for the gaseous species. These uncertainties stem mainly from the emissions factors and from the differing size distributions of particles emitted from different source groups. There are also particle sources known to exist but difficult to quantify. This includes biogenic sources (pollen, biogenic debris etc.), wind blown dust from agricultural sources, natural surfaces, or from construction work and re-suspension of road dust. In addition, the often unknown representativeness and accuracy of measurements are additional sources of errors that have to be kept in mind during model evaluation. In light of the various error sources affecting $\mathrm{PM}_{10}$, the only small average underestimation of $\mathrm{PM}_{10}$ by RCG is a very positive result.

\subsection{Seasonal variation}

The seasonal variation for $\mathrm{PM}_{10}$, sulphate, nitrate, ammonium, EC and OC from October 2001 to September 2002 is depicted in Fig. 3 for the urban background site Nansensstrasse as an example. For $\mathrm{PM}_{10}$, a clear seasonal cycle neither appears in observations, nor in simulations. Only in June and July, the concentrations are somewhat lower. For sulphate, most of the model underestimation evident in the annual mean is concentrated in the cold season (November to April). For nitrate, much larger levels are observed in the cold season than in summer and this seasonal variation is well captured by the model. The major reason is the smaller saturation pressure of $\mathrm{NH}_{4} \mathrm{NO}_{3}$ for colder winter temperatures. For ammonium, the seasonal variation is similar as for nitrate, but with a smaller amplitude. This seasonal variation is less evident in the simulations. A similar behaviour in the observed and simulated seasonal variation is also apparent for the other HOVERT sites.

For EC at urban sites, the seasonal variation is not very clear, but a minimum appears both in observations and simulations in late spring/early summer (May to July). Also for rural sites, no clear seasonal variation is observed or simulated. For OC, data are available only between May and September. In both observations and simulations, OC levels are larger in August and September. In the simulations, the higher concentrations are due to higher secondary OC concentrations.

In conclusion, when a clear seasonal variation is evident in observations, as especially for nitrate, it is also reproduced by the model. The largest discrepancy in the simulated seasonal variation is the sulphate model underestimation during winter. The fact that the seasonal variation (or its absence) is well represented by the model is encouraging. Apparently, the overall seasonality of a series of processes is well represented in RCG: Dispersion of primary PM emissions, secondary PM formation, advection to the Berlin area, wet and dry deposition. 

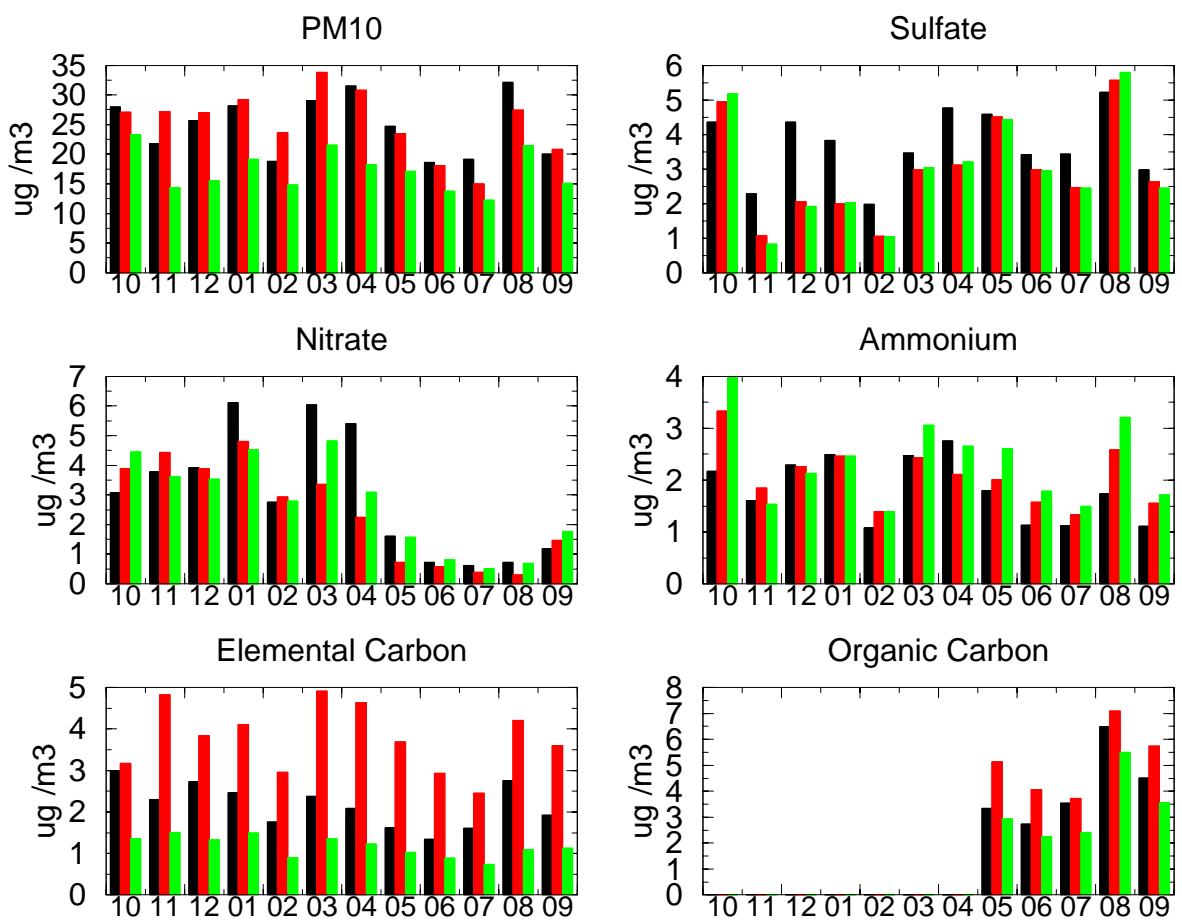

Fig. 3. Observed and simulated (with the nested and continental scale model) seasonal variation for PM 10 , Sulphate, Nitrate, Ammonium, EC and OC at an urban background site (Nansenstasse). Black bars show observations, red bars nested simulations and green bars continental scale simulations.

\subsection{Day to day variability}

The correct representation of day-to-day variability of $\mathrm{PM}_{10}$ and its chemical components in RCG is evaluated from inspection of time series (Fig. 4), analysis of correlation coefficients between daily means (Fig. 5) and normalised root mean square errors.

The time series of simulated and observed $\mathrm{PM}_{10}$ at the urban background station Nansenstrasse shows good general agreement. Only few $\mathrm{PM}_{10}$ episodes are missed; however, several ones are overestimated, especially in the cold season. The annual correlation coefficient for this site is 0.63 , the values for other HOVERT sites range from 0.46 to 0.73 . Correlation coefficients are in general about 0.1 larger during the warm season (taken here between May and September) than during the cold season (between October to April).

For sulphate and ammonium, inspection of time series (Figs. 4b and d) also shows good agreement. Most of the peaks coincide, but several are also overestimated or missing in simulations. Strong $\mathrm{NH}_{4}^{+}$peaks (and under-, overestimations) are in general linked to similar peaks of either $\mathrm{SO}_{4}^{2-}$ or $\mathrm{NO}_{3}^{-}$. Figure 5 shows average correlation coefficients for $\mathrm{SO}_{4}^{2-}$ and $\mathrm{NH}_{4}^{+}$of, respectively, 0.70 and 0.72 for nested simulations and 0.72 and 0.74 for the large scale simulations. For sulphate, correlation coefficients are similar in the warm and cold season; for ammonium on the contrary, they are 0.1 to 0.15 larger in the cold season. Probably, the good correlation in these time series is driven by different transport regimes made evident by trajectory analysis and which seem to be well taken into account in the model (E. Reimer, personal communication): larger observed and simulated $\mathrm{SO}_{4}^{2-}$ and $\mathrm{NH}_{4}^{+}$values in the Berlin region are related to transport from the east and south east sector where strong $\mathrm{SO}_{2}$ sources are present (in Saxony, Southern Poland) while lower values are more related to transport from the western sector under low pressure conditions. Nearly identical correlation coefficients for the continental and the nested simulations are coherent with this interpretation.

For nitrate, the high annual correlation coefficient is driven by the strong seasonal variation. For each the cold and warm season alone, correlation coefficients are in the range 0.4 to 0.7 and 0.2 to 0.4 . This lower correlation coefficients for $\mathrm{NO}_{3}^{-}$than for $\mathrm{SO}_{4}^{2-}$ reflects the larger complexity for particulate nitrate formation. Contrary to $\mathrm{SO}_{4}^{2-}$ which is present in the particle phase only, $\mathrm{NO}_{3}^{-}$is in equilibrium with gaseous $\mathrm{HNO}_{3}$. The partitioning between both phases depends on the total nitrate, ammonium and sulphate availability and environmental parameters (temperature, humidity), which all can have errors.

EC is consistently overestimated at the urban background station, in particular peak values during the cold season. Days with overestimated EC values often correspond to days 


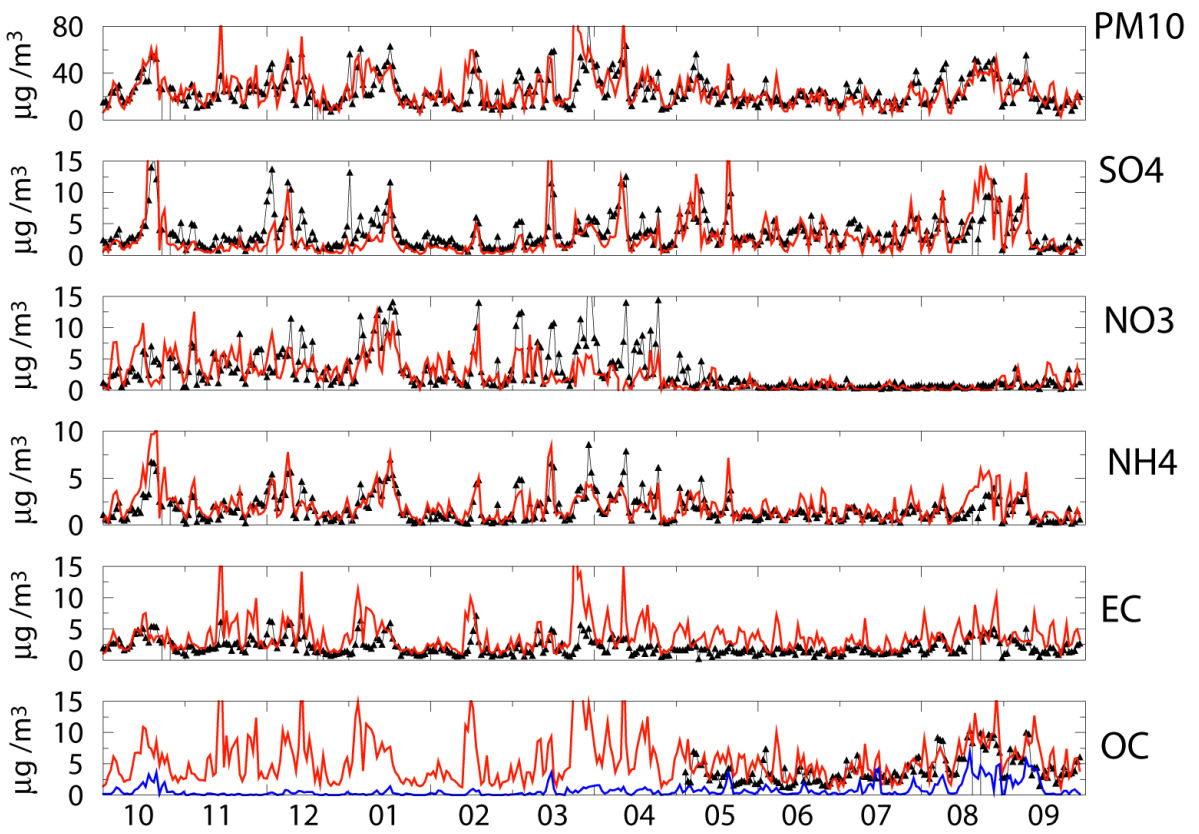

Fig. 4. Observed and simulated (with the nested model) time series for $\mathrm{PM}_{10}$, Sulphate, Nitrate, Ammonium, EC and OC at an urban background site: thin line with triangle observations, thick red line: simulations, for OC, thin blue line: SOA simulations.

with overestimated $\mathrm{PM}_{10}$, thus this overestimation probably concerns PM of primary origin in general and may be due either to too large emissions in the urban area or to too small dilution. As seen before, this overestimation is specific only for the urban background site. The average over annual correlation coefficients at different HOVERT sites is 0.38 for the nested and 0.44 for the large scale model, respectively, with no particular seasonal tendency. This means that the spatial refinement in the model resolution also leads to the introduction of some additional noise in the model, as for instance possible errors in the urban emission inventory, which are "diffused" in the large scale data set with a higher spatial aggregation. It also has to be mentioned that the number of urban meteorological sites included in the optimum interpolation procedure is very small. Thus, the urban heat island effect might be not well resolved in the meteorological data base leading to too stable conditions, particularly in the night and in winter time. This discussion is relevant for all locally emitted primary species (EC, primary $\mathrm{OC}$ and $\mathrm{PM}_{10}$ ).

OC measurements were available at the urban background site only from May on. The correlation $(\mathrm{R}=0.5-0.6)$ for the nested version is mainly due to correlations between simulated secondary $\mathrm{OC}$ and observed $\mathrm{OC}(\mathrm{R}=\sim 0.6)$, while primary OC only poorly correlates with observed OC $(\mathrm{R}=0.1-$ 0.4 ). Even if secondary OC only contributes to about $20 \%$ to the total simulated one for the urban and suburban sites and to about $40 \%$ for rural sites, its variability is much stronger than that of primary OC (many days with near zero levels, episodic peaks, see Fig. 4). As noted before, especially the large OC values in the second half of August and first half

\section{Correlation coefficients}

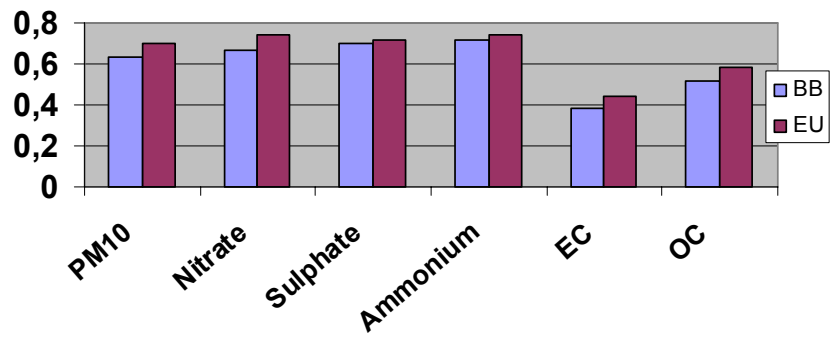

Fig. 5. Average correlation between simulations and observations over HOVERT sites: $\mathrm{PM}_{10}$, Sulphate, Nitrate, Ammonium, EC and OC.

of September are due to secondary OC formation and largely contribute to the good correlation. This period is also related to enhanced observed and simulated photooxidant levels $\left(\mathrm{O}_{3}+\mathrm{NO}_{2}\right)$ pointing to an enhanced photochemical activity.

Normalised root mean square errors (NRMSE) both reflect errors in the day to day variability and systematic biases (for a definition, see for example Schaap et al., 2004a; Hass et al., 2003). Typical values for HOVERT sites for a year period and nested simulations are about $50 \%$ for $\mathrm{PM}_{10}, 60-70 \%$ for $\mathrm{SO}_{4}^{2-}, 60-80 \%$ for $\mathrm{NH}_{4}^{+}, 80-110 \%$ for $\mathrm{NO}_{3}^{-}, 60-140 \%$ for $\mathrm{EC}$ and $50-70 \%$ for OC.

In conclusion, correlation coefficients are satisfying (0.60.8 ) for $\mathrm{PM}_{10}, \mathrm{SO}_{4}^{2-}, \mathrm{NH}_{4}^{+}$and secondary $\mathrm{OC}$, but less good for $\mathrm{NO}_{3}^{-}$and primary $\mathrm{OC}$ and $\mathrm{EC}$. As discussed before, for 
$\mathrm{SO}_{4}^{2-}$ and $\mathrm{NH}_{4}^{+}$, correlation seems to be driven by transport patterns (transport from source regions located in the southeast sector). For EC and OC, smaller correlation coefficients and the fact that the refinement in model resolution does not lead to better correlation, indicate that the day-to-day variability in urban scale processes (emissions, horizontal and vertical dispersion) is difficult to represent in the input data bases.

\section{Discussion}

\subsection{Inorganic ions}

In this section, starting with inorganic ions, we compare the results from this work with those obtained in former comparison studies in light of model and measurement uncertainty. Average differences for sulphate (over a set of over 40 EMEP sites) were in general within a range of $\pm 20 \%$ in earlier evaluation studies for different European air quality models (Hass et al., 2003; Bessagnet et al., 2004; Schaap et al., 2004a), in accordance to our results for the HOVERT sites. However, average correlation is better in this work (0.72) than in previous studies (in the range 0.3-0.7). This may reflect the different set of sites studied, but also the refined formulation of the $\mathrm{SO}_{2}$ to $\mathrm{SO}_{4}^{2-}$ aqueous phase conversion in the RCG model, which takes into account relative humidity, $\mathrm{O}_{3}$ and $\mathrm{H}_{2} \mathrm{O}_{2}$ concentrations. Still, uncertainty in simulated $\mathrm{SO}_{4}^{2-}$ is large, as it crucially depends on the cloud liquid water content, which is not available from the observed meteorological fields and which had to be estimated for typical low level clouds.

For nitrate, a significant part of differences could also stem from uncertainties in the measurements. Especially, filter techniques as used for this comparison are subject to evaporation of nitrate (and ammonium) above about $20^{\circ} \mathrm{C}$ (e.g. Schaap et al., 2004a). Thus, part of the overestimation at rural sites during HOVERT (Paulinenaue $+17 \%$, Hasenholz $+86 \%$ ) and part of the overestimation encountered in previous studies (Hass et al., 2004) could be explained by measurement uncertainty. Besides, simulated nitrate concentrations depend of a variety of aerosol component or gaseous species concentrations with their own uncertainty, like sulphate, total nitrate $\left(\mathrm{HNO}_{3}+\mathrm{NO}_{3}^{-}\right)$, on total ammonium $\left(\mathrm{NH}_{4}^{+}+\mathrm{NH}_{3}\right)$; it also depends on the equilibrium between particulate $\mathrm{NH}_{4} \mathrm{NO}_{3}$ and gaseous precursors calculated by ISORROPIA as a function of humidity and temperature. This large number of error sources is reflected in the lower correlation coefficients, in the range of $0.2-0.4$ in the warm season, and 0.4-0.7 in the cold season, in line with results from previous evaluations (Hass et al., 2003; Bessagnet et al., 2004; Schaap et al., 2004a).

The ammonium overestimation of ten to several ten $\%$ may again be partly explained by $\mathrm{NH}_{4} \mathrm{NO}_{3}$ evaporation from the filter. Besides, it depends on the model uncertainties al- ready noted for $\mathrm{SO}_{4}^{2-}$ and $\mathrm{NO}_{3}^{-}$. These average deviations are smaller than those in the EUROTRAC evaluation ranging from $-45 \%$ to $+87 \%$ (Hass et al., 2003). Also, as already for sulphate, the average annual correlation coefficient is better in this work ( $\mathrm{R}=0.72$ average over all HOVERT sites) than in previous work ( $\mathrm{r}=0.4-0.6$ ) (Hass et al., 2003; Bessagnet et al., 2004; Schaap et al., 2004a).

\subsection{Elemental carbon}

The average differences between EC simulations and observations are not larger than about $\pm 70 \%$ for different sites. This can be judged as a positive result in the light of the large uncertainties affecting the comparisons including emissions (1), model transport and dispersion (2), removal processes (3), measurement accuracy (4) and representativity of measurement sites (5). To constrain the possible influence of these different uncertainty sources, we separately discuss the results for urban/traffic and rural sites.

For the urban site Nansenstrasse and the traffic site Frankfurter Allee, simultaneous $\mathrm{EC}$ and $\mathrm{NO}_{\mathrm{x}}$ measurements allow normalising out effects of transport and the representativity of measurement sites. Indeed, simulated daily $\mathrm{EC}$ and $\mathrm{NO}_{\mathrm{x}}$ averages are highly correlated at both sites ( $r \sim 0.9)$, which indicates that emissions of both species show similar spatial and temporal patterns. In addition, removal processes are not important for these near source locations. In practice, normalised simulated daily $\mathrm{EC}$ averages $\left(\mathrm{EC}_{\text {sim,norm }}\right)$ are obtained by multiplying the originally simulated EC average $\mathrm{EC}_{\text {sim }}$ by the ratio of observed to simulated daily average $\mathrm{NO}_{\mathrm{x}}$ :

$\mathrm{EC}_{\text {sim,norm }}=\mathrm{EC}_{\text {sim }} \times \mathrm{NO}_{\text {xobs }} / \mathrm{NO}_{\text {xsim }}$

The ratio of the annual averages in $\mathrm{EC}_{\text {sim,norm }}$ and $\mathrm{EC}_{\mathrm{obs}}$ and the slope in their scatter plot (not shown) are indicated in Table 3. Note that the slope refers here to a fitting line minimizing the square of distances to the data points. For the urban background site, the effect of the normalisation is only small. However, at the traffic site Frankfurter Allee, the normalization procedure increases $\mathrm{EC}$ because simulated $\mathrm{NO}_{\mathrm{x}}$ is underestimated (as the specific high emission environment of a street cannot be taken into account in an urban-scale model application). For Beusselstr., the other traffic site, $\mathrm{NO}_{\mathrm{x}}$ data are not available, and the method can not be applied. Both concentration ratios and slopes in Table 3 indicate a strong overestimation of simulated $\mathrm{EC}$ with respect to $\mathrm{NO}_{\mathrm{x}}$, between a factor 1.4 and 2.0. This overestimation might even be larger, if one takes into account that EC measurements performed after the VDI 2564/2 method (see Sect. 3) showed larger values than obtained with other methods Schmid et al., 2001; ten Brink et al., 2004). If assuming unbiased $\mathrm{NO}_{\mathrm{x}}$ measurements and emissions, these results would point to an overestimation in urban EC emissions. As described in chapter 2, $\mathrm{EC}$ emissions have been derived in an indirect manner from PM emissions by using EC/PM partition coefficients 
Table 3. Observed and simulated $\mathrm{EC}$ and $\mathrm{NO}_{\mathrm{x}}$ annual averages for urban and traffic sites and derived quantities. $\mathrm{EC}_{\text {sim.,norm. }}$ denotes $\mathrm{EC}$ normalised by $\mathrm{NO}_{\mathrm{x}}$, see text for explanation. Slope denotes the slope of the $\mathrm{EC}_{\text {sim.,norm. }}$ versus $\mathrm{EC}_{\mathrm{obs}}$ scatter plot (daily means).

\begin{tabular}{lllllll}
\hline & $\begin{array}{l}\mathrm{EC}_{\text {obs }} \\
\left(\mu \mathrm{g} / \mathrm{m}^{3}\right)\end{array}$ & $\begin{array}{l}\mathrm{EC}_{\text {sim }} \\
\left(\mu \mathrm{g} / \mathrm{m}^{3}\right)\end{array}$ & $\begin{array}{l}\mathrm{NO}_{\text {xobs }} \\
\left(\mu \mathrm{g} / \mathrm{m}^{3}\right)\end{array}$ & $\begin{array}{l}\mathrm{NO}_{\text {xsim }} \\
\left(\mu \mathrm{g} / \mathrm{m}^{3}\right)\end{array}$ & $\begin{array}{l}\mathrm{EC}_{\text {sim,norm. }} \text { vs. } \mathrm{EC}_{\text {obs }} \\
\text { Ratio }\end{array}$ & Slope \\
\hline Frankfurter Allee & 4.28 & 2.57 & 64.2 & 27.7 & 1.39 & 1.68 \\
Nansenstr. & 2.16 & 3.78 & 32.9 & 30.0 & 1.92 & 2.00 \\
\hline
\end{tabular}

for each SNAP sector. Thus, uncertainty in EC emissions includes that in PM emissions and that in EC/PM emission ratios. Moreover, these ratios reflect average European conditions and thus may not be suitable for the pecific Berlin conditions. Indeed, a specific EC (and OC) emission inventory for the Berlin area would be highly desirable, but is not available yet.

In contrast to the urban sites, EC simulations are underestimated for rural sites by about a factor of two.

To our knowledge, no other systematic comparison with a dense network of measurements sites providing daily EC samples for a whole year has been performed so far. Preliminary comparisons of simulations with the EMEP model in 2002 and 2003 with measurements for 14 mainly rural sites during July 2002 to April 2003 (one sample per week) show a model underestimation between a factor of 1.5 to 3 for rural sites (Tørseth et al., 2004; Yttri et al., 2005). Schaap et al. (2004b) also find an EC underestimation with the LOTUS model by a factor of two and more for rural sites, using climatological observations (generally not taken at the same time as simulations). These underestimations are qualitatively in line with results from our study also showing a model underestimation for rural sites. Comparisons of simulations with the EPA CMAQ model show differences with observations obtained at various U.S. sites during the IMPROVE campaign mainly between factors of \pm 2 (Yu et al., 2004). Interestingly, as in our study, overestimations are more common for urban sites, and underestimations for rural sites.

Uncertainties in measurements could explain this difference given the large differences in EC measurement techniques (up to a factor of 4) made evident for measurements at rural locations (ten Brink et al., 2004) (and which are stronger than uncertainties at urban sites).

On the model side, both Schaap et al. (2004) and Tørseth et al. (2004) propose an underestimation of European wide EC emissions as a possible explanation. Clearly, other error sources are also possible, for example a too strong dilution in the LOTUS model with only one layer covering the whole mixing layer. Besides, removal processes of EC might be overestimated, due to the fact that EC (as OC) is considered to be mixed with other more hydrophilic components within individual particles (internal mixing). In fact, isolation of a single error source among the different uncertainties stated above is not possible.

\subsection{Organic carbon}

Organic carbon consists of a primary and a secondary part, which are not discerned by measurements. Simulated secondary organic carbon correlates better with measurements than does the primary one ( $r=\sim 0.6$ versus $r=0.1$ to 0.4$)$, even it accounts only for about $20-40 \%$ of total simulated OC. Attempts have been made in the literature to derive primary $\mathrm{OC}$ to EC ratios from observations by sorting out measurements containing secondary OC using a criterion on photochemical activity (Russel and Allen, 2004) or by considering only a fraction of data with the lowest ratios (Yu et al., 2004). Such methods were tentatively employed here, but did not to give stable enough results for the purpose of a quantitative model evaluation, i.e. the derived $\mathrm{OC}^{\mathrm{prim}} / \mathrm{EC}$ ratio significantly varied for different sub-sets of data.

Alternatively, we use again scaling with other compounds to get information about the different error sources affecting primary and secondary OC simulations. Provided that spatial and temporal patterns of EC and OC emissions and removal processes are similar, scaling of simulated primary OC with the ratio of observed to simulated EC allows to normalise out several error sources: errors in absolute emissions (but not in the ratio in OC/EC emissions), in transport and dispersion, in removal (as far as independent of aerosol type) and in the representativity of sites located close to sources:

$\mathrm{OC}_{\text {sim }, \text { norm }}=\mathrm{OC}_{\text {sim }}^{\text {prim }} \times \mathrm{EC}_{\mathrm{obs}} / \mathrm{EC}_{\mathrm{sim}}+\mathrm{OC}_{\mathrm{sim}}^{\mathrm{sec}}$

Results in Table 4 indicate a significant improvement in correlation (by 0.1 to 0.3 ) due to the scaling procedure; correlation coefficients between $\mathrm{OC}_{\text {sim, norm }}$ and $\mathrm{OC}_{\text {sobs }}$ range now between 0.72 and 0.82 , slopes are near unity (between 0.86 and 1.14 , note that slope again refers to a fitting line minimizing squares of distances with data points). This is attributed to "correction" of the above mentioned error sources. Error sources which have not been subject to normalising (OC/EC emission ratio, the simulation of secondary $\mathrm{OC}$, and measurement errors of OC and EC) thus lead only to a small bias, but as a matter of evidence, error compensation can not be excluded. If the OC/EC emission ratio was correct, then urban OC emissions (like EC) would appear to be overestimated.

The simulated OC ${ }^{\text {prim} / E C ~ r a t i o ~ o b t a i n e d ~ i n ~ o u r ~ s t u d y ~ c a n ~}$ be qualitatively compared to "pseudo" observations from other studies. Our values between 1.2 and 1.4 are well within 
Table 4. Correlation coefficients and slopes for simulated and observed OC with and without adjustment by EC.

\begin{tabular}{llllll}
\hline & \multicolumn{2}{l}{$\mathrm{OC}_{\text {sim }}$ vs. OC } & \multicolumn{2}{l}{$\mathrm{OC}_{\text {sim, norm }}$ vs. $\mathrm{OC}_{\text {obs }}$} & \multirow{2}{*}{$\mathrm{N}$} \\
& $\mathrm{R}$ & Slope & $\mathrm{R}$ & Slope & $\mathrm{N}$ \\
\hline Frankfurter Allee (traffic) & 0.54 & 0.64 & 0.72 & 1.14 & 131 \\
Beusselstr. (traffic) & 0.48 & 0.98 & 0.72 & 1.05 & 83 \\
Nansenstr. (urban background) & 0.54 & 1.14 & 0.82 & 1.04 & 146 \\
Schichauer Weg (sub-urban) & 0.59 & 0.65 & 0.79 & 0.86 & 103 \\
Paulinenaue (rural) & 0.66 & 0.94 & 0.74 & 1.00 & 218 \\
\hline
\end{tabular}

the range of values reported at several urban and rural sites, between 1.1 and 1.9, with one outlier at 4.6 (Yu et al., 2004).

From the OC/EC scaling procedure, no particular bias for SOA could be inferred. Correlation between simulated SOA and total observed OC of about 0.6 also indicate that the simulated SOA variability partly reflects reality. These results are satisfying in light of the uncertainties related to SOA modelling including VOC and in particular terpene emissions, saturation pressure of VOC oxidation products, the problems of SOA aging, the polymerisation of SOA compounds (e.g. Kalberer et al., 2004), SOA dependence on preexisting aerosols, SOA wet and dry removal, and many more.

\section{Conclusion and perspectives}

During the HOVERT campaign (from September 2001 to September 2002), a unique data base of the particulate matter chemical speciation of has been gathered at several sites in the Berlin-Brandenburg area in Germany. These observations are used for a thorough evaluation of the aerosol part in the REM-CALGRID (RCG) model developed at the Free University of Berlin. For inorganic ions (sulphate, nitrate and ammonium), simulated annual averages agree to observations within $\pm 30 \%$ for more than half of the sites, and always within a factor of two. Averaged over all HOVERT sites, the model shows a tendency for a too large nitrate to sulphate ratio, but the sum of sulphate, nitrate and ammonium agrees within 5\% to observations. These results are satisfying; they are in the order of previous comparison exercises. The seasonal variations are, when present, in general well depicted, with the exception of a $\mathrm{SO}_{4}^{2-}$ deficiency in winter/spring time simulations. Correlation coefficients are larger for $\mathrm{SO}_{4}^{2-}$ and $\mathrm{NH}_{4}^{+}(>0.7)$ than in previous model evaluation studies. This is ascribed to a good model representation of the transport patterns into the Berlin urban area, leading to large transport values from the south-east sector (Poland, Saxonia), and lower values from the western sector. It may also reflect progress in the parameterization of the $\mathrm{SO}_{2}$ to $\mathrm{SO}_{4}^{2-}$ conversion, although model uncertainties are still large, especially in regard of the estimation of cloud water content from relative humidity and the removal processes. For nitrate, correlation is lower, which is ascribed to additional uncertainty in the thermodynamic equilibrium calculation between $\mathrm{NH}_{4} \mathrm{NO}_{3}$ and its gaseous precursors.

To our knowledge, this is one of the first comparisons of air quality model simulated elemental carbon (EC) with daily observations at several sites and over a time span of up to one year. It suggests an overestimation of EC emissions in the Berlin area (through a scaling technique with $\mathrm{NO}_{\mathrm{x}}$, and under the assumption that $\mathrm{NO}_{\mathrm{x}}$ emissions are correct). The underestimation of $\mathrm{EC}$ at rural sites could be due either to an underestimation in background EC emissions, a too fast EC removal and/or a positive bias in observations.

Organic carbon (OC) shows a similar picture as EC, with a probable urban emission overestimation, and an underestimation at rural sites. Scaling of OC with EC shows that there is no significant bias in the combination of three error sources: OC/EC emission ratios, secondary organic aerosol (SOA) formation during VOC oxidation, and measurement errors in the OC/EC ratio. Although error compensation cannot be excluded, these results give some credit to the crude description of $\mathrm{OC} / \mathrm{EC}$ emission ratios in the model and to the correctness of the SORGAM SOA formation scheme. Also the correlation coefficients around 0.6 between SOA and measured OC indicate that the model depicts part of the variability in SOA formation.

The overestimation of urban $\mathrm{EC}$ and $\mathrm{OC}$ and the rural underestimation together may lead to a "local" bias of the model in the Berlin area, i.e. differences between urban and regional background levels are overestimated by the model. This local bias may have an effect also on $\mathrm{PM}_{10}$ levels: for days with a significant EC overestimation at the urban background site, also $\mathrm{PM}_{10}$ is overestimated. These considerations are important to be taken in mind when using the model for budget studies (see Kerschbaumer et al., 2007 ${ }^{1}$ ).

As an overall conclusion, in our opinion, this evaluation study has helped to gain increasing confidence in simulations of chemical constituents of particulate matter with the RCG model. It also has made evident some model and input data deficiencies: sulphate underestimation during winter/spring time, nitrate overestimation at rural sites, an EC and OC underestimation at rural sites, an indication for EC and OC emission overestimation in the Berlin area. As a next step, it would be interesting to use this very detailed HOVERT data 
set for a broader evaluation exercise including other European air quality models.

\section{Appendix A}

\section{List of acronyms}

\begin{tabular}{|c|c|}
\hline CBM-4 & carbon bond mechanism, version 4 \\
\hline CTM & chemistry-transport model \\
\hline $\mathrm{EC}$ & elemental carbon \\
\hline EMEP & $\begin{array}{l}\text { Co-operative program for monitoring and } \\
\text { evaluation of the long range transmissions } \\
\text { of air pollutants in Europe }\end{array}$ \\
\hline EURAD & $\begin{array}{l}\text { Europäisches Ausbreitungs und Deposi- } \\
\text { tionsmodell }\end{array}$ \\
\hline EPA & Environmental Protection Agency \\
\hline HOVERT & $\begin{array}{l}\text { Horizontal and vertical transport of ozone } \\
\text { and particulate matter }\end{array}$ \\
\hline $\mathrm{OC}$ & organic carbon \\
\hline PM & particulate matter \\
\hline $\mathrm{PM}_{1}$ & $\begin{array}{l}\text { particulate matter with a dynamical diame- } \\
\text { ter below } 1 \mu \mathrm{m}\end{array}$ \\
\hline $\mathrm{PM}_{2.5}$ & $\begin{array}{l}\text { particulate matter with a dynamical diame- } \\
\text { ter below } 2.5 \mu \mathrm{m}\end{array}$ \\
\hline $\mathrm{PM}_{10}$ & $\begin{array}{l}\text { particulate matter with a dynamical diame- } \\
\text { ter below } 10 \mu \mathrm{m}\end{array}$ \\
\hline RCG & REM-CALGRID model \\
\hline SAPRC & $\begin{array}{l}\text { Statewide Air Pollution Research Center } \\
\text { Chemical mechanism }\end{array}$ \\
\hline SIA & Secondary inorganic ions \\
\hline SNAP & Selected Nomenclature for Air Pollution \\
\hline SOA & Secondary organic carbon \\
\hline SORGAM & Secondary organic aerosol model \\
\hline VOC & Volatile organic compounds \\
\hline
\end{tabular}

Acknowledgements. The HOVERT project was supported by the AFO-2000 program set-up by the German Federal Ministery of Research and Technology (BMFT). An additional observational site (Beusselstr.) was run with the support of the Senat Berlin. The development of the REM-CALGRID model was supported by the German Federal Environmental Agency (Umweltbundesamt) within the R\&D-projects 29841252 and 29943 246. Matthias Beekmann was on sabbatical leave at Freie Universität Berlin during September 2002 to August 2003 and was supported by CNRS (France).

Edited by: S. Martin

\section{References}

Bessagnet, B., Hodzic, A., Vautard, R., Beekmann, M., Cheinet, S., Honoré, C., Liousse, C., and Rouil, L.: Aerosol modelling with CHIMERE - preliminary evaluation at the continental scale, Atmos. Environ., 38, 2803-2817, 2004

Bond, T. C., Streets, D. G., Yarber, K. F., Nelson, S. M., Woo, J. H., and Klimont, Z.: A technology-based global inventory of Black and Organic Carbon emissions from Combustion, J. Geophys. Res., 109, D14203, doi:10.1029/2003JD003697, 2004.

Builtjes, P. J. H.: Aerosols over Europe, Focus on Black carbon, TNO report R2003/146, February 2003.

Carter, W.: Condensed atmospheric photooxidation mechanisms for isoprene, Atmos. Environ., 30, 4275-4290, 1996.

Claiborn, C., Lamb, B., Miller, A., Beseda, J., Clode, B., Vaughan, J., Kang, L., and Nevine, C.: Regional measurements and modeling of windblown agricultural dust: The Columbia Plateau $\mathrm{PM}_{10}$ Program, J. Geophys. Res., 103(D16), 19753-19767, 1998.

Erisman, J. W., Van Pul, A., and Wyers, P.: Parameterization of surface resistance for the quantification of atmospheric deposition of acidifying pollutants and ozone, Atmos. Environ., 28, 25952607, 1994.

Gery, M., Witten, G., and Killus, J.: A photochemical kinetics mechanism for urban scale and regional scale computer modelling, J. Geophys. Res., 94(D10), 12 925-12 956, 1989.

Gong, S. L., Barrie, L. A., and Blanchet, J.-P.: Modelling sea-salt aerosols in the atmosphere. 1. Model development, J. Geophys. Res., 102, 3805-3818, 1997.

Guenther, A. B., Zimmerman, P. R., Harley, P. C., Monson, R. K. and Fall, R.: Isoprene and monoterpene emission rate variability: Model evaluations and sensitivity analyses, J. Geophys. Res., 98(D7), 12 609-12 618, 1993.

Hass, H., Builtjes, P. J. H., Simpson, D., and Stern, R.: Comparison of model results obtained with several European regional air quality models, Atmos. Environ., 31, 3259-3279, 1997.

Hass, H., Van Loon, M., Kessler, C., Stern, R., Matthijsen, J., Sauter, F., Zlatev, Z., Langner, J., Foltescu, V., and Schaap, M.: Aerosol modelling: results and intercomparison from European regional scale modelling systems, EUROTRAC-2 special report, GSF, Munich, Germany, 2003.

Hodzic, A., Chepfer, H., Chazette, P., Beekmann, M., Bessagnet, B., Drobinski, P., Goloub, P. Haeffelin, M., Morille, Y., and Vautard R.: Comparison of aerosol chemistry transport simulations with lidar and sun-photometer observations at a site near Paris, J. Geophys. Res., J. Geophys. Res., D23201, doi:10.1029/2004JD004735, 2004.

John, A. and Kuhlbusch, T.: Bericht zur Qualitätssicherung des Projekts, Ursachenanalyse von Feinstaub $\left(\mathrm{PM}_{10}\right)$ Imissionen in Berlin auf der Basis von Messungen der Staubinhaltsstoffe am Stadtrand, in der Innenstadt und in einer Strassenschlucht, IUTA Bericht Nr. LP 13/2004“, 2004.

Kalberer, M., Paulsen, D., Sax, M. Steinbacher, M., Dommen, J., Prevot, A. S. H., Fisseha, R., Weingartner, E., Frankevich, V., Zenobi, R., and Baltensperger, U.: Identification of Polymers as Major Components of Atmospheric Organic Aerosols, Science, 303, 1659-1662, 2004.

Kanakidou, M., Seinfeld, J. H., Pandis, S. N., Barnes, I., Dentener, F. J., Facchini, M. C., Van Dingenen, R., Ervens, B., Nenes, A., Nielsen, C. J., Swietlicki, E., Putaud, J. P., Balkanski, Y., Fuzzi, S., Horth, J., Moortgat, G. K., Winterhalter, R., Myhre, C. E. L., Tsigaridis, K., Vignati, E., Stephanou, E. G., and Wilson, J.: Organic aerosol and global climate modelling: a review, Atmos. Chem. Phys., 5, 1053-1123, 2005, http://www.atmos-chem-phys.net/5/1053/2005/.

Kerschbaumer, A. and Reimer, R.: Erstellung meteorologischer Eingangsdaten für das REM/CALGRID Modell: Modellregion Berlin-Brandenburg, Berichte zum UBA Forschungsvorhaben 
29943 246, Freie Universität Berlin, Institut für Meteorologie, 2003.

Limbeck, A., Rend, J., Heimburger, G., Kranabetter, A., and Puxbaum, H.: Seasonal variation of palladium, elemental carbon and aerosol mass concentrations in airborne particulate matter, Atmos. Environ., 38, 1979-1987, 2004.

Loosmore, G. A. and Hunt, J. R.: Dust resuspension without saltation, J. Geophys. Res., 105(D16), 20 663-20671, doi:10.1029/2000JD900271, 2000.

Nenes, A., Pilinis, C., and Pandis, S. N.: Continued development and testing of a new thermodynamic aerosol module for urban and regional air quality models, Atmos. Environ., 33, 15531560, 1999.

Odum, J. R., Hoffmann, T., Bowman, F., Collins, D., Flagan, R. C., and Seinfeld, J. H.: Gas/Particle partitioning and secondary organic aerosol yields, Environ. Sci. Technol., 30, 2580-2585, 1996.

Padro, J.: Seasonal contrasts of modelled and observed dry deposition velocities of $\mathrm{O}_{3}, \mathrm{NO}_{2}$ and $\mathrm{SO}_{2}$ over three surfaces, Atmos. Environ., 27, 807-814, 1993.

Reimer, E. und Scherer, B.: An operational meteorological diagnostic system for regional air pollution analysis and long term modeling, in: Air Pollution Modelling and its Application IX, edited by: v. Dop, H. and Kallos, G., NATO Challenges of Modern Society, Kluwer Academic/Plenum Publisher, New York, 1992.

Römer, M., Beekmann, M., Bergström, R., Boersen, G., Feldmann, H., Flatøy, F., Honore, C., Langner, J., Jonson, J. E., Matthijsen, J., Memmesheimer, M., Simpson, D., Smeets, P., Solberg, S., Stern, R., Stevenson, D., Zandveld, P., and Zlatev, Z.: Ozone trends according to ten dispersion models, EUROTRAC-2 special report, GSF, Munich, Germany, 2003.

Russel, M. and Allen, D. T.: Seasonal and spatial trends in primary and secondary organic aerosol carbon concentrations in southeast Texas, Atmos. Environ., 38, 3225-3239, 2004.

Schmid, H., Laskus, L., Abraham, H. J., Baltensberger, U., Lavanchy, V., Bizjak, M., Burba, P., Cachier, H., Crow, D., Chow, J., Gnauk, T., Even, A., ten Brink, H. M., Giesen, K. P., Hitzenberger, R., Yueglin, C. H., Maenhut, W., Pio, C., Carvalho, A., Putaud, J. P., Toom-Sauntry, D., and Puxbaum, H.: Results of the "carbon conference" international carbon round robin test stage I, Atmos. Environ., 35, 2111-2121, 2001.

Schaap, M., van Loon, M., ten Brink, H. M., Dentener, F. J., and Builtjes, P. J. H.: Secondary inorganic aerosol simulations for Europe with special attention to nitrate, Atmos. Chem. Phys., 4, 857-874, 2004a.

Schaap, M., Van Der Gon, H. A. C. D., Visschedijk, A. J. H., Van Loon, M., ten Brink, H. M., Dentener, F. J., Putaud, J.-P., Guillaume, B., Liousse, C., and Builtjes, P. J. H.: Anthropogenic Black Carbon and Fine Aerosol Distribution over Europe, J. Geophys. Res., 109, D18207, doi:10.1029/2003JD004330, 2004b.

Schell, B., Ackermann, I. J., Hass, H., Binkowski, F., and Ebel, A.: Modelling the formation of secondary organic aerosol within a comprehensive air quality model system, J. Geophys. Res., 106(D22), 28 275-28 293, 2001.

Seinfeld, J. and Pandis, S. N.: Atmospheric Chemistry and Physics, John Wiley and Sons, 1998.
Stern, R.: Entwicklung und Anwendung eines dreidimensionalen photochemischen Ausbreitungsmodells, Meteorologische Abhandlungen Serie A, Band 8, Institut für Meteorologie der FUBerlin, 1994.

Stern, R.: Entwicklung und Anwendung des chemischen Transportmodells REM/CALGRID. Berichte zum UBA Forschungsvorhaben 29841 252, Freie Universität Berlin, Institut für Meteorologie, 2003.

Stern, R., Yamartino, R., and Graff, A.: Dispersion modelling within the European Community's Air Quality Directives: long term modelling of O3, $\mathrm{PM}_{10}$ and NO2, 26th ITM on Air Pollution Modelling and its Application, 26-30 May 2003, Istanbul, Turkey, 2003.

Simpson, D., Guenther, A., Hewitt, C. N., and Steinbrecher, R.: Biogenic emissions in Europe, 1, Estimates and uncertainties, J. Geophys. Res., 100(D11), 22 875-22 890, 1995.

Simpson, D., Winiwarter, W. , Börjesson, G., Cinderby, S., Ferreiro, A., Guenther, A., Hewitt, C.N., Janson, R., Khalil, M. A. K., Owen, S., Pierce, T. E., Puxbaum, H., Shearer, M., Skiba, U., Steinbrecher, R., Tarrasón, L., and Öquist, M. G.: Inventorying emissions from nature in Europe, J. Geophys. Res., 104(D7), 8113-8152, 1999.

ten Brink, H., Maenhaut, W., Hitzenberger, R., Gnauk, T., Spindler, G., Even, A., Chi, X., Bauer, H., Puxbaum, H., Putaud, J. P., Tursic, J., and Berner, A.: INTERCOMP2000: the comparability of methods in use in Europe for measuring the carbon content of aerosol, Atmos. Environ., 38, 3259-3279, 2004.

Tilmes, S., Brandt, J., Flat $\varnothing y$, F., Bergström, R., Flemming, J., Langner, J., Christensen, J. H., Frohn, L. M., Hov, Ø., Jacobsen, I., Reimer, E., Stern, R., and Zimmermann, J.: Comparison of five eulerian air pollution systems for the summer 1999 using the German ozone monitoring data, J. Atmos. Chem., 42, 91-121, 2002.

Tørseth, K. (Ed.): Transboundary particulate matter in Europe, EMEP status report, August 2004.

van Loon, M., Roemer, M. G. M., Builtjes, P. J. H., Bessagnet, B., Rouil, L., Christensen, J., Brandt, J., Fagerli, H., Tarrason, L., Rodgers, I., Teasdale, I., Stern, R., Bergström, R., Langner, J., and Foltescu, V.: Model intercomparison in the framework of the review of the Unified EMEP model. TNO-report R2004/282, 53 pp., available at: http://www.mep.tno.nl, 2004.

Vestreng, V.: Review and revision of emissions reported to CLRTAP, EMEP status report, July 2003.

Walcek, C. J.: Minor flux adjustment near mixing ratio extremes for simplified yet highly accurate monotonic calculation of tracer advection, J. Geophys. Res., 105(D7), 9335-9348, 2000.

Yamartino, R. J., Scire, J. S, Charmichael, G. R., and Chang, Y. S.: The CALGRID mesoscale photochemical grid model-I. Model formulation, Atmos. Environ., 26A, 1493-1512, 1992.

Yttri, K. E. and Tørseth, K. (Eds.): Transboundary particulate matter in Europe, EMEP status report, August 2004.

Yu, S., Dennis, R. L., Bhave, P. V., and Eder, B. K.: Primary and secondary organic aerosol over the United States: estimates on the basis of observed organic carbon (OC) and elemental carbon (EC), and air quality modeled primary OC/EC ratios, Atmos. Environ., 38, 5257-5268, 2004. 